This PDF is a selection from an out-of-print volume from the National Bureau of Economic Research

Volume Title: The Rate and Direction of Inventive Activity: Economic and Social Factors

Volume Author/Editor: Universities-National Bureau Committee for Economic Research, Committee on Economic Growth of the Social Science Research Council

Volume Publisher: Princeton University Press

Volume ISBN: 0-87014-304-2

Volume URL: http://www.nber.org/books/univ62-1

Publication Date: 1962

Chapter Title: Economic Welfare and the Allocation of Resources for Invention

Chapter Author: Kenneth Arrow

Chapter URL: http://www.nber.org/chapters/c2144

Chapter pages in book: (p. $609-626)$ 


\title{
Economic Welfare and the Allocation of Resources for Invention
}

\author{
KENNETH J. ARROW \\ THE RAND CORPORATION
}

INVENTION is here interpreted broadly as the production of knowledge. From the viewpoint of welfare economics, the determination of optimal resource allocation for invention will depend on the technological characteristics of the invention process and the nature of the market for knowledge.

The classic question of welfare economics will be asked here: to what extent does perfect competition lead to an optimal allocation of resources? We know from years of patient refinement that competition insures the achievement of a Pareto optimum under certain hypotheses. The model usually assumes among other things, that (1) the utility functions of consumers and the transformation functions of producers are well-defined functions of the commodities in the economic system, and (2) the transformation functions do not display indivisibilities (more strictly, the transformation sets are convex). The second condition needs no comment. The first seems to be innocuous but in fact conceals two basic assumptions of the usual models. It prohibits uncertainty in the production relations and in the utility functions, and it requires that all the commodities relevant either to production or to the welfare of individuals be traded on the market. This will not be the case when a commodity for one reason or another cannot be made into private property.

We have then three of the classical reasons for the possible failure of perfect competition to achieve optimality in resource allocation: indivisibilities, inappropriability, and uncertainty. The first problem has been much studied in the literature under the heading of marginalcost pricing and the second under that of divergence between social and private benefit (or cost), but the theory of optimal allocation of resources under uncertainty has had much less attention. I will summarize what formal theory exists and then point to the critical notion of information, which arises only in the context of uncertainty. The

Note: I have benefited greatly from the comments of my colleague, William Capron. I am also indebted to Richard R. Nelson, Edward Phelps, and Sidney Winter of The RAND Corporation for their helpful discussion. 
economic characteristics of information as a commodity and, in particular, of invention as a process for the production of information are next examined. It is shown that all three of the reasons given above for a failure of the competitive system to achieve an optimal resource allocation hold in the case of invention. On theoretical grounds a number of considerations are adduced as to the likely biases in the misallocation and the implications for economic organization. ${ }^{1}$

\section{Resource Allocation under Uncertainty}

The role of the competitive system in allocating uncertainty seems to have received little systematic attention. ${ }^{2}$ I will first sketch an ideal economy in which the allocation problem can be solved by competition and then indicate some of the devices in the real world which approximate this solution.

Suppose for simplicity that uncertainty occurs only in production relations. Producers have to make a decision on inputs at the present moment, but the outputs are not completely predictable from the inputs. We may formally describe the outputs as determined by the inputs and a "state of nature" which is unknown to the producers. Let us define a "commodity-option" as a commodity in the ordinary sense labeled with a state of nature. This definition is analogous to the differentiation of a given physical commodity according to date in capital theory or according to place in location theory. The production of a given commodity under uncertainty can then be described as the production of a vector of commodity-options.

This description can be most easily exemplified by reference to agricultural production. The state of nature may be identified with the weather. Then, to any given set of inputs there corresponds a number of bushels of wheat if the rainfall is good and a different number if rainfall is bad. We can introduce intermediate conditions of rainfall

\footnotetext{
${ }^{1}$ For other analyses with similar points of view, see R. R. Nelson, "The Simple Economics of Basic Scientific Research," Journal of Political Economy, 1959, pp. 297-306; and C. J. Hitch, "The Character of Research and Development in a Competitive Economy," The RAND Corporation, p. 1297, May 1958.

${ }^{2}$ The first studies I am aware of are the papers of M. Allais and myself, both presented in 1952 to the Colloque International sur le Risque in Paris; see M. Allais, "Généralisation des théories de l'équilibre économique général et du rendement social au cas du risque," and K. J. Arrow, "Rôle des valeurs bousières pour la répartition la meilleure des risques," both in Economètrie, Colloques Internationaux du Centre National de la Recherche Scientifique, Vol. XL, Paris, Centre National de la Recherche Scientifique, 1953. Allais' paper has also appeared in Econometrica, 1953, pp. 269-290. The theory has received a very elegant generalization by G. Debreu in Theory of Values, New York, Wiley, 1959, Chap. VII.
} 
in any number as alternative states of nature; we can increase the number of relevant variables which enter into the description of the state of nature, for example by adding temperature. By extension of this procedure, we can give a formal description of any kind of uncertainty in production.

Suppose-and this is the critical idealization of the economy-we have a market for all commodity-options. What is traded on each market are contracts in which the buyers pay an agreed sum and the sellers agree to deliver prescribed quantities of a given commodity if a certain state of nature prevails and nothing if that state of nature does not occur. For any given set of inputs, the firm knows its output under each state of nature and sells a corresponding quantity of commodity-options; its revenue is then completely determined. It may choose its inputs so as to maximize profits.

The income of consumers is derived from their sale of supplies, including labor, to firms and their receipt of profits, which are assumed completely distributed. They purchase commodity-options so as to maximize their expected utility given the budget restraint imposed by their incomes. An equilibrium is reached on all commodity-option markets, and this equilibrium has precisely the same Pareto-optimality properties as competitive equilibrium under certainty.

In particular, the markets for commodity-options in this ideal model serve the function of achieving an optimal allocation of risk bearing among the members of the economy. This allocation takes account of differences in both resources and tastes for risk bearing. Among other implications, risk bearing and production are separated economic functions. The use of inputs, including human talents, in their most productive mode is not inhibited by unwillingness or inability to bear risks by either firms or productive agents.

But the real economic system does not possess markets for commodity-options. To see what substitutes exist, let us first consider a model economy at the other extreme, in that no provisions for reallocating risk bearing exist. Each firm makes its input decisions; then outputs are produced as determined by the inputs and the state of nature. Prices are then set to clear the market. The prices that finally prevail will be a function of the state of nature.

The firm and its owners cannot relieve themselves of risk bearing in this model. Hence any unwillingness or inability to bear risks will give rise to a nonoptimal allocation of resources, in that there will be 
discrimination against risky enterprises as compared with the optimum. A preference for risk might give rise to misallocation in the opposite direction, but the limitations of financial resources are likely to make underinvestment in risky enterprises more likely than the opposite. The inability of individuals to buy protection against uncertainty similarly gives rise to a loss of welfare.

In fact, a number of institutional arrangements have arisen to mitigate the problem of assumption of risk. Suppose that each firm and individual in the economy could forecast perfectly what prices would be under each state of nature. Suppose further there were a lottery on the states of nature, so that before the state of nature is known any individual or firm may place bets. Then it can be seen that the effect from the viewpoint of any given individual or firm is the same as if there were markets for commodity-options of all types, since any commodity-option can be achieved by a combination of a bet on the appropriate state of nature and an intention to purchase or sell the commodity in question if the state of nature occurs.

References to lotteries and bets may smack of frivolity, but we need only think of insurance to appreciate that the shifting of risks through what are in effect bets on the state of nature is a highly significant phenomenon. If insurance were available against any conceivable event, it follows from the preceding discussion that optimal allocation would be achieved. Of course, insurance as customarily defined covers only a small range of events relevant to the economic world; much more important in shifting risks are securities, particularly common stocks and money. By shifting freely their proprietary interests among different firms, individuals can to a large extent bet on the different states of nature which favor firms differentially. This freedom to insure against many contingencies is enhanced by the alternatives of holding cash and going short.

Unfortunately, it is only too clear that the shifting of risks in the real world is incomplete. The great predominance of internal over external equity financing in industry is one illustration of the fact that securities do not completely fulfill their allocative role with respect to risks. There are a number of reasons why this should be so, but I will confine myself to one, of special significance with regard to invention. In insurance practice, reference is made to the moral factor as a limit to the possibilities of insurance. For example, a fire insurance policy cannot exceed in amount the value of the goods insured. From the purely actuarial standpoint, there is no reason for this limitation; 
the reason for the limit is that the insurance policy changes the incentives of the insured, in this case, creating an incentive for arson or at the very least for carelessness. The general principle is the difficulty of distinguishing between a state of nature and a decision by the insured. As a result, any insurance policy and in general any device for shifting risks can have the effect of dulling incentives. A fire insurance policy, even when limited in amount to the value of the goods covered, weakens the motivation for fire prevention. Thus, steps which improve the efficiency of the economy with respect to risk bearing may decrease its technical efficiency.

One device for mitigating the adverse incentive effects of insurance is coinsurance; the insurance extends only to part of the amount at risk for the insured. This device is used, for example, in coverage of medical risks. It clearly represents a compromise between incentive effects and allocation of risk bearing, sacrificing something in both directions.

Two exemplifications of the moral factor are of special relevance in regard to highly risky business activities, including invention. Success in such activities depends on an inextricable tangle of objective uncertainties and decisions of the entrepreneurs and is certainly uninsurable. On the other hand, such activities should be undertaken if the expected return exceeds the market rate of return, no matter what the variance is. ${ }^{3}$ The existence of common stocks would seem to solve the allocation problem; any individual stockholder can reduce his risk by buying only a small part of the stock and diversifying his portfolio to achieve his own preferred risk level. But then again the actual managers no longer receive the full reward of their decisions; the shifting of risks is again accompanied by a weakening of incentives to efficiency. Substitute motivations whether pecuniary, such as executive compensation and profit sharing, or nonpecuniary, such as prestige, may be found, but the dilemma of the moral factor can never be completely resolved.

A second example is the cost-plus contract in one of its various forms. When production costs on military items are highly uncertain, the military establishment will pay, not a fixed unit price, but the cost of production plus an amount which today is usually a fixed fee. Such a contract could be regarded as a combination of a fixed-price contract with an insurance against costs. The insurance premium could be

${ }^{3}$ The validity of this statement depends on some unstated assumptions, but the point to be made is unaffected by minor qualifications. 
regarded as the difference between the fixed price the government would be willing to pay and the fixed fee.

Cost-plus contracts are necessitated by the inability or unwillingness of firms to bear the risks. The government has superior risk bearing ability and so the burden is shifted to it. It is then enabled to buy from firms on the basis of their productive efficiency rather than their risk bearing ability, which may be only imperfectly correlated. But cost-plus contracts notoriously have their adverse allocative effects. ${ }^{4}$

This somewhat lengthy digression on the theory of risk bearing seemed necessitated by the paucity of literature on the subject. The main conclusions to be drawn are the following: (1) the economic system has devices for shifting risks, but they are limited and imperfect: hence, one would expect an underinvestment in risky activities; (2) it is undoubtedly worthwhile to enlarge the variety of such devices, but the moral factor creates a limit to their potential.

\section{Information as a Commodity}

Uncertainty usually creates a still more subtle problem in resource allocation; information becomes a commodity. Suppose that in one part of the economic system an observation has been made whose outcome, if known, would affect anyone's estimates of the probabilities of the different states of nature. Such observations arise out of research but they also arise in the daily course of economic life as a by-product of other economic activities. An entrepreneur will automatically acquire a knowledge of demand and production conditions in his field which is available to others only with special effort. Information will frequently have an economic value, in the sense that anyone possessing the information can make greater profits than would otherwise be the case.

It might be expected that information will be traded in, and of course to a considerable extent this is the case, as is illustrated by the numerous economic institutions for transmission of information, such as newspapers. But in many instances, the problem of an optimal allocation is sharply raised. The cost of transmitting a given body of information is frequently very low. If it were zero, then optimal allocation would obviously call for unlimited distribution of the informa-

\footnotetext{
4 These remarks are not intended as a complete evaluation of cost-plus contracts. In particular, there are, to a certain extent, other incentives which mitigate the adverse effects on efficiency.
} 
tion without cost. In fact, a given piece of information is by definition an indivisible commodity, and the classical problems of allocation in the presence of indivisibilities appear here. The owner of the information should not extract the economic value which is there, if optimal allocation is to be achieved; but he is a monopolist, to some small extent and will seek to take advantage of this fact.

In the absence of special legal protection, the owner cannot, however, simply sell information on the open market. Any one purchaser can destroy the monopoly, since he can reproduce the information at little or no cost. Thus the only effective monopoly would be the use of the information by the original possessor. This, however, will not only be socially inefficient, but also may not be of much use to the owner of the information either, since he may not be able to exploit it as effectively as others.

With suitable legal measures, information may become an appropriable commodity. Then the monopoly power can indeed be exerted. However, no amount of legal protection can make a thoroughly appropriable commodity of something so intangible as information. The very use of the information in any productive way is bound to reveal it, at least in part. Mobility of personnel among firms provides a way of spreading information. Legally imposed property rights can provide only a partial barrier, since there are obviously enormous difficulties in defining in any sharp way an item of information and differentiating it from other similar sounding items.

The demand for information also has uncomfortable properties. In the first place, the use of information is certainly subject to indivisibilities; the use of information about production possibilities, for example, need not depend on the rate of production. In the second place, there is a fundamental paradox in the determination of demand for information; its value for the purchaser is not known until he has the information, but then he has in effect acquired it without cost. Of course, if the seller can retain property rights in the use of the information, this would be no problem, but given incomplete appropriability, the potential buyer will base his decision to purchase information on less than optimal criteria. He may act, for example, on the average value of information in that class as revealed by past experience. If any particular item of information has differing values for different economic agents, this procedure will lead both to a nonoptimal purchase of information at any given price and also to a nonoptimal allocation of the information purchased. 
It should be made clear that from the standpoint of efficiently distributing an existing stock of information, the difficulties of appropriation are an advantage, provided there are no costs of transmitting information, since then optimal allocation calls for free distribution. The chief point made here is the difficulty of creating a market for information if one should be desired for any reason.

It follows from the preceding discussion that costs of transmitting information create allocative difficulties which would be absent otherwise. Information should be transmitted at marginal cost, but then the demand difficulties raised above will exist. From the viewpoint of optimal allocation, the purchasing industry will be faced with the problems created by indivisibilities; and we still leave unsolved the problem of the purchaser's inability to judge in advance the value of the information he buys. There is a strong case for centralized decision making under these circumstances.

\section{Invention as the Production of Information}

The central economic fact about the processes of invention and research is that they are devoted to the production of information. By the very definition of information, invention must be a risky process, in that the output (information obtained) can never be predicted perfectly from the inputs. We can now apply the discussion of the preceding two sections.

Since it is a risky process, there is bound to be some discrimination against investment in inventive and research activities. In this field, especially, the moral factor will weigh heavily against any kind of insurance or equivalent form of risk bearing. Insurance against failure to develop a desired new product or process would surely very greatly weaken the incentives to succeed. The only way, within the private enterprise system, to minimize this problem is the conduct of research by large corporations with many projects going on, each small in scale compared with the net revenue of the corporation. Then the corporation acts as its own insurance company. But clearly this is only an imperfect solution.

The deeper problems of misallocation arise from the nature of the product. As we have seen, information is a commodity with peculiar attributes, particularly embarrassing for the achievement of optimal allocation. In the first place, any information obtained, say a new method of production, should, from the welfare point of view, be 
available free of charge (apart from the cost of transmitting information). This insures optimal utilization of the information but of course provides no incentive for investment in research. In an ideal socialist economy, the reward for invention would be completely separated from any charge to the users of the information. ${ }^{5}$ In a free enterprise economy, inventive activity is supported by using the invention to create property rights; precisely to the extent that it is successful, there is an underutilization of the information. The property rights may be in the information itself, through patents and similar legal devices, or in the intangible assets of the firm if the information is retained by the firm and used only to increase its profits.

The first problem, then, is that in a free enterprise economy the profitability of invention requires a nonoptimal allocation of resources. But it may still be asked whether or not the allocation of resources to inventive activity is optimal. The discussion of the preceding section makes it clear that we would not expect this to be so; that, in fact, a downward bias in the amount of resources devoted to inventive activity is very likely. Whatever the price, the demand for information is less than optimal for two reasons: (1) since the price is positive and not at its optimal value of zero, the demand is bound to be below the optimal; (2) as seen before, at any given price, the very nature of information will lead to a lower demand than would be optimal.

As already remarked, the inventor will in any case have considerable difficulty in appropriating the information produced. Patent laws would have to be unimaginably complex and subtle to permit such appropriation on a large scale. Suppose, as the result of elaborate tests, some metal is discovered to have a desirable property, say resistance to high heat. Then of course every use of the metal for which this property is relevant would also use this information, and the user would be made to pay for it. But, even more, if another inventor is stimulated to examine chemically related metals for heat resistance, he is using the information already discovered and should pay for it in some measure; and any beneficiary of his discoveries should also pay. One would have to have elaborate distinctions of partial property rights of all degrees to make the system at all tolerable. In the interests of the possibility of enforcement, actual patent laws sharply restrict the range of appropriable information and thereby reduce the incentives to engage in inventive and research activities.

\footnotetext{
${ }^{5}$ This separation exists in the Soviet Union, according to N. M. Kaplan and R. H. Moorsteen of The RAND Corporation (verbal communication).
} 
These last considerations bring into focus the interdependence of inventive activities, which reinforces the difficulties in achieving an optimal allocation of the results. Information is not only the product of inventive activity, it is also an input-in some sense, the major input apart from the talent of the inventor. The school of thought that emphasizes the determination of invention by the social climate as demonstrated by the simultaneity of inventions in effect emphasizes strongly the productive role of previous information in the creation of new information. While these interrelations do not create any new difficulties in principle, they intensify the previously established ones. To appropriate information for use as a basis for further research is much more difficult than to appropriate it for use in producing commodities; and the value of information for use in developing further information is much more conjectural than the value of its use in production and therefore much more likely to be underestimated. Consequently, if a price is charged for the information, the demand is even more likely to be suboptimal.

Thus basic research, the output of which is only used as an informational input into other inventive activities, is especially unlikely to be rewarded. In fact, it is likely to be of commercial value to the firm undertaking it only if other firms are prevented from using the information obtained. But such restriction on the transmittal of information will reduce the efficiency of inventive activity in general and will therefore reduce its quantity also. We may put the matter in terms of sequential decision making. The a priori probability distribution of the true state of nature is relatively flat to begin with. On the other hand, the successive a posteriori distributions after more and more studies have been conducted are more and more sharply peaked or concentrated in a more limited range, and we therefore have better and better information for deciding what the next step in research shall be. This implies that, at the beginning, the preferences among alternative possible lines of investigation are much less sharply defined than they are apt to be later on and suggests, at least, the importance of having a wide variety of studies to begin with, the less promising being gradually eliminated as information is accumulated. ${ }^{6}$ At each stage the decisions about the next step should be based on all available information. This would require an unrestricted flow of informa-

- The importance of parallel research developments in the case of uncertainty has been especially stressed by Burton H. Klein; see his, "A Radical Proposal for R. and D.," Fortune, May 1958, p. 112 ff.; and Klein and W. H. Meckling, "Application of Operations Research to Development Decisions," Operations Research, 1958, pp. 352-363. 
tion among different projects which is incompatible with the complete decentralization of an ideal free enterprise system. When the production of information is important, the classic economic case in which the price system replaces the detailed spread of information is no longer completely applicable.

To sum up, we expect a free enterprise economy to underinvest in invention and research (as compared with an ideal) because it is risky, because the product can be appropriated only to a limited extent, and because of increasing returns in use. This underinvestment will be greater for more basic research. Further, to the extent that a firm succeeds in engrossing the economic value of its inventive activity, there will be an underutilization of that information as compared with an ideal allocation.

\section{Competition, Monopoly, and the Incentive to Innovate}

It may be useful to remark that an incentive to invent can exist even under perfect competition in the product markets though not, of course, in the "market" for the information contained in the invention. This is especially clear in the case of a cost reducing invention. Provided only that suitable royalty payments can be demanded, an inventor can profit without disturbing the competitive nature of the industry. The situation for a new product invention is not very different; by charging a suitable royalty to a competitive industry, the inventor can receive a return equal to the monopoly profits.

I will examine here the incentives to invent for monopolistic and competitive markets, that is, I will compare the potential profits from an invention with the costs. The difficulty of appropriating the information will be ignored; the remaining problem is that of indivisibility in use, an inherent property of information. A competitive situation here will mean one in which the industry produces under competitive conditions, while the inventor can set an arbitrary royalty for the use of his invention. In the monopolistic situation, it will be assumed that only the monopoly itself can invent. Thus a monopoly is understood here to mean barriers to entry; a situation of temporary monopoly, due perhaps to a previous innovation, which does not prevent the entrance of new firms with innovations of their own, is to be regarded as more nearly competitive than monopolistic for the purpose of this analysis. It will be argued that the incentive to invent is less under monopolistic than under competitive conditions but even in the latter case it will be less than is socially desirable. 
We will assume constant costs both before and after the invention, the unit costs being $c$ before the invention and $c^{\prime}<c$ afterward. The competitive price before invention will therefore be $c$. Let the corresponding demand be $x_{c}$. If $r$ is the level of unit royalties, the competitive price after the invention will be $c^{\prime}+r$, but this cannot of course be higher than $c$, since firms are always free to produce with the old methods.

It is assumed that both the demand and the marginal revenue curves are decreasing. Let $R(x)$ be the marginal revenue curve. Then the monopoly output before invention, $x_{m}$, would be defined by the equation,

$$
R\left(x_{m}\right)=c .
$$

Similarly, the monopoly output after invention is defined by,

$$
R\left(x_{m}^{\prime}\right)=c^{\prime} .
$$

Let the monopoly prices corresponding to outputs $x_{m}$ and $x_{m}^{\prime}$, respectively, be $p_{m}$ and $p_{m}^{\prime}$. Finally, let $P$ and $P^{\prime}$ be the monopolist's profits before and after invention, respectively.

What is the optimal royalty level for the inventor in the competitive case? Let us suppose that he calculates $p_{m}^{\prime}$, the optimal monopoly price which would obtain in the postinvention situation. If the cost reduction is sufficiently drastic that $p_{m}^{\prime}<c$, then his most profitable policy is to set $r$ so that the competitive price is $p_{m}^{\prime}$, i.e. let,

$$
r=p^{\prime}{ }_{m}-c^{\prime} \text {. }
$$

In this case, the inventor's royalties are equal to the profits a monopolist would make under the same conditions, i.e. his incentive to invent will be $P^{\prime}$.

Suppose, however, it turns out that $p_{m}^{\prime}>c$. Since the sales price cannot exceed $c$, the inventor will set his royalties at,

$$
r=c-c^{\prime} \text {. }
$$

The competitive price will then be $c$, and the sales will remain at $x_{c}$. The inventor's incentive will then be, $x_{c}\left(c-c^{\prime}\right)$.

The monopolist's incentive, on the other hand, is clearly $P^{\prime}-P$. In the first of the two cases cited, the monopolist's incentive is obviously less than the inventor's incentive under competition, which is $P^{\prime}$, not $P^{\prime}-P$. The preinvention monopoly power acts as a strong disincentive to further innovation. 
The analysis is slightly more complicated in the second case. The monopolist's incentive, $P^{\prime}-P$, is the change in revenue less the change in total cost of production, i.e.,

$$
P^{\prime}-P=\int_{x_{m}}^{x_{m}^{\prime}} R(x) d x-c^{\prime} x_{m}^{\prime}+c x_{m} .
$$

Since the marginal revenue $R(x)$ is diminishing, it must always be less than $R\left(x_{m}\right)=c$ as $x$ increases from $x_{m}$ to $x_{m}^{\prime}$, so that,

$$
\int_{x_{m}}^{x_{m}^{\prime}} R(x) d x<c\left(x^{\prime}{ }_{m}-x_{m}\right),
$$

and,

$$
P^{\prime}-P<c\left(x_{m}^{\prime}-x_{m}\right)-c^{\prime} x_{m}^{\prime}+c x_{m}=\left(c-c^{\prime}\right) x_{m}^{\prime} .
$$

In the case being considered, the postinvention monopoly price, $p_{m}^{\prime}$, is greater than $c$. Hence, with a declining demand curve, $x_{m}^{\prime}<x_{c}$. The above inequality shows that the monopolist's incentive is always less than the cost reduction on the postinvention monopoly output, which in this case is, in turn, less than the competitive output (both before and after invention). Since the inventor's incentive under competition is the cost reduction on the competitive output, it will again always exceed the monopolist's incentive.

It can be shown that, if we consider differing values of $c^{\prime}$, the difference between the two incentives increases as $c^{\prime}$ decreases, reaching its maximum of $P$ (preinvention monopoly profits) for $c^{\prime}$ sufficiently large for the first case to hold. The ratio of the incentive under competition to that under monopoly, on the other hand, though always greater than 1 , decreases steadily with $c^{\prime}$. For $c^{\prime}$ very close to $c$ (i.e., very minor inventions), the ratio of the two incentives is approximately $x_{c} / x_{m}$, i.e., the ratio of monopoly to competitive output. ${ }^{?}$

${ }^{7}$ To sketch the proof of these statements quickly, note that, as $c^{\prime}$ varies, $P$ is a constant. Hence, from the formula for $\boldsymbol{P}^{\prime}-P$, we see that,

$$
d\left(P^{\prime}-P\right) / d c^{\prime}=d P^{\prime} / d c^{\prime}=R\left(x_{m}^{\prime}\right)\left(d x_{m}^{\prime} / d c^{\prime}\right)-c^{\prime}\left(d x_{m}^{\prime} / d c^{\prime}\right)-x_{m}^{\prime}=-x_{m}^{\prime},
$$

since $R\left(x_{m}^{\prime}\right)=c^{\prime}$. Let $F\left(c^{\prime}\right)$ be the difference between the incentives to invent under competitive and under monopolistic conditions. In the case where $p_{m}^{\prime} \leqslant c$, this difference is the constant $P$. Otherwise,

$$
F\left(c^{\prime}\right)=x_{c}\left(c-c^{\prime}\right)-\left(P^{\prime}-P\right)
$$

so that

$$
d F / d c^{\prime}=x_{m}^{\prime}-x_{c} .
$$

For the case considered, we must have $x_{m}^{\prime}<x_{c}$, as seen in the text. Hence, $d F / d c^{\prime} \leq 0$, so 
The only ground for arguing that monopoly may create superior incentives to invent is that appropriability may be greater under monopoly than under competition. Whatever differences may exist in this direction must, of course, still be offset against the monopolist's disincentive created by his preinvention monopoly profits.

The incentive to invent in competitive circumstances may also be compared with the social benefit. It is necessary to distinguish between the realized social benefit and the potential social benefit, the latter being the benefit which would accrue under ideal conditions, which, in this case, means the sale of the product at postinvention cost, $c^{\prime}$. Clearly, the potential social benefit always exceeds the realized social benefit. I will show that the realized social benefit, in turn, always equals or exceeds the competitive incentive to invent and, a fortiori, the monopolist's incentive.

Consider again the two cases discussed above. If the invention is sufficiently cost reducing so that $p^{\prime}{ }_{m}<c$, then there is a consumers' benefit, due to the lowering of price, which has not been appropriated by the inventor. If not, then the price is unchanged, so that the consumers' position is unchanged, and all benefits do go to the inventor. Since by assumption all the producers are making zero profits both before and after the invention, we see that the inventor obtains the entire realized social benefit of moderately cost reducing inventions but not of more radical inventions. Tentatively, this suggests a bias against major inventions, in the sense that an invention, part of whose costs could be paid for by lump-sum payments by consumers without making them worse off than before, may not be profitable at the maximum royalty payments that can be extracted by the inventor.

that $F\left(c^{\prime}\right)$ increases as $c^{\prime}$ decreases.

Let $G(c)$ be the ratio of the incentive under competition to that under monopoly. If $p_{m}^{\prime} \leqslant c$, then,

$$
G\left(c^{\prime}\right)=P^{\prime} /\left(P^{\prime}-P\right),
$$

which clearly decreases as $c^{\prime}$ decreases. For $\boldsymbol{p}_{m}^{\prime}>c$, we have,

$$
G\left(c^{\prime}\right)=x_{c}\left(c-c^{\prime}\right) /\left(P^{\prime}-P\right) \text {. }
$$

Then,

$$
d G / d c^{\prime}=\left[-\left(P^{\prime}-P\right) x_{c}+x_{c}\left(c-c^{\prime}\right) x_{n}^{\prime}\right] /\left(P^{\prime}-P\right)^{2} .
$$

Because of the upper bound for $\boldsymbol{P}^{\prime}-\boldsymbol{P}$ established in the text, the numerator must be positive; the ratio decreases as $c^{\prime}$ decreases.

Finally, if we consider $c^{\prime}$ very close to $c, G\left(c^{\prime}\right)$ will be approximately equal to the ratio of the derivatives of the numerator and denominator (L'Hopital's rule), which is, $x_{\epsilon} / x^{\prime}{ }_{m}$, and which approaches $x_{c} / x_{m}$ as $c^{\prime}$ approaches $c$. 


\section{Alternative Forms of Economic Organization in Invention}

The previous discussion leads to the conclusion that for optimal allocation to invention it would be necessary for the government or some other agency not governed by profit-and-loss criteria to finance research and invention. In fact, of course, this has always happened to a certain extent. The bulk of basic research has been carried on outside the industrial system, in universities, in the government, and by private individuals. One must recognize here the importance of nonpecuniary incentives, both on the part of the investigators and on the part of the private individuals and governments that have supported research organizations and universities. In the latter, the complementarity between teaching and research is, from the point of view of the economy, something of a lucky accident. Research in some more applied fields, such as agriculture, medicine, and aeronautics, has consistently been regarded as an appropriate subject for government participation, and its role has been of great importance.

If the government and other nonprofit institutions are to compensate for the underallocation of resources to invention by private enterprise, two problems arise: how shall the amount of resources devoted to invention be determined, and how shall efficiency in their use be encouraged? These problems arise whenever the government finds it necessary to engage in economic activities because indivisibilities prevent the private economy from performing adequately (highways, bridges, reclamation projects, for example), but the determination of the relative magnitudes is even more difficult here. Formally, of course, resources should be devoted to invention until the expected marginal social benefit there equals the marginal social benefit in alternative uses, but in view of the presence of uncertainty, such calculations are even more difficult and tenuous than those for public works. Probably all that could be hoped for is the estimation of future rates of return from those in the past, with investment in invention being increased or decreased accordingly as some average rate of return over the past exceeded or fell short of the general rate of return. The difficulties of even ex post calculation of rates of return are formidable though possibly not insuperable. ${ }^{8}$

The problem of efficiency in the use of funds devoted to research

${ }^{8}$ For an encouraging study of this type, see Z. Griliches, "Research Costs and Social Returns: Hybrid Corn and Related Innovations," Journal of Political Economy, 1958, pp. 419-431. 
is one that has been faced internally by firms in dealing with their own research departments. The rapid growth of military research and development has led to a large-scale development of contractual relations between producers and a buyer of invention and research. The problems encountered in assuring efficiency here are the same as those that would be met if the government were to enter upon the financing of invention and research in civilian fields. The form of economic relation is very different from that in the usual markets. Payment is independent of product; it is governed by costs, though the net reward (the fixed fee) is independent of both. This arrangement seems to fly in the face of the principles for encouraging efficiency, and doubtless it does lead to abuses, but closer examination shows both mitigating factors and some explanation of its inevitability. In the first place, the awarding of new contracts will depend in part on past performance, so that incentives for efficiency are not completely lacking. In the second place, the relation between the two parties to the contract is something closer than a purely market relation. It is more like the sale of professional services, where the seller contracts to supply not so much a specific result as his best judgment. (The demand for such services also arises from uncertainty and the value of information.) In the third place, payment by results would involve great risks for the inventor, risks against which, as we have seen, he could hedge only in part.

There is clear need for further study of alternative methods of compensation. For example, some part of the contractual payment might depend on the degree of success in invention. But a more serious problem is the decision as to which contracts to let. One would need to examine the motivation underlying government decision making in this area. Hitch has argued that there are biases in governmental allocation, particularly against risky invention processes, and an excessive centralization, though the latter could be remedied by better policies. ${ }^{9}$

One can go further. There is really no need for the firm to be the fundamental unit of organization in invention; there is plenty of reason to suppose that individual talents count for a good deal more than the firm as an organization. If provision is made for the rental of necessary equipment, a much wider variety of research contracts with individuals as well as firms and with varying modes of payment, including incentives, could be arranged. Still other forms of organiza-

${ }^{\circ}$ Op. cit. 
tion, such as research institutes financed by industries, the government, and private philanthropy, could be made to play an even livelier role than they now do.

\section{COMMENT}

\section{J. Hitch, The RAND Corporation}

There is, I think, one important aspect of government policy with respect to research and development that Markham failed to discussthe government's contracting and management policies in this area. The problems here are related to Arrow's discussion of incentives, particularly his remarks concerning risk bearing and the adverse allocative effects of cost-plus contracts.

Let me illustrate one set of such problems by contrasting the management policies used by the Army Air Corps before World War II in developing new combat aircraft with the policies now used by the Air Force in developing aircraft and missiles.

Before the war the Air Corps would typically announce a competition for a new aircraft type, the desired characteristics of which would be described in general terms. Any aircraft company that wanted to enter the competition would develop and build, with its own funds, the required number of prototypes (usually one to three). The competition consisted in flying and testing, at Dayton, the prototypes entered by the companies. The prize for the winner was a production contract. The losers lost their stake.

Now, typically, the competition occurs at the design stage. The competing companies enter drawings, with their estimates of performance (and time and cost of development). The winner of the design competition is awarded a development contract which, if things go favorably, is transformed later into a production contract. Occasionally, if the program is considered very important, two competing designs may be approved for development or even production (cf. the Atlas and Titan). But usually the development of more than one model is considered too expensive.

In fact, the greatly increased cost of development is the reason given for this change in policy. When the cost of developing a new vehicle is from $\$ 0.5$ billion to $\$ 2.0$ billion, it seems evident that no aircraft company can assume the risk, and perhaps also that even the government can not finance multiple developments. 
Nevertheless, the new policy appears far from ideal. The aircraft companies risk nothing (even the cost of preparing designs is usually reimbursed). Because of the great uncertainties involved in any major development, it is hard to make a wise selection at the design stage. Companies have a natural tendency to be optimistic in estimating performance, cost, and availability at this stage-sometimes much more so than at other stages as Klein and Marshall and Meckling have shown. And the Air Force has a natural tendency to favor the more optimistic proposals. As a result, the specifications in the development contract are sometimes unrealistic to the point of causing inordinate delay.

Moreover, once the winner has been selected, there is no more competition. The company may put its best team on the development for the sake of patriotism or its own long term reputation, but the powerful incentive of competition is lacking. Partly for this reason the Air Force, locked to a sole source with a cost-plus contract, has to exercise a kind and degree of control during the development process that is inconsistent with management prerogatives as they are understood and practiced in other parts of the free enterprise economy.

I believe the inefficiencies resulting from these policies and procedures are serious, and worthy of much more attention by economists. It does no good simply to inveigh against the iniquities of cost-plus contracting and government risk bearing when we are unable to propose a practical alternative. Perhaps part of the answer lies in some form of risk sharing. What is badly needed here is an economics invention or, more probably, several of them. The government is going to be in the business of supporting research and development on a large scale for a long time, and it is important that it use policies that take advantage of the incentives present in the economy. 